\title{
THE EFFECT OF ESTONIAN FOLK DANCE PRACTICE ON STATIC BALANCE PERFORMANCE IN YOUNG FEMALES
}

\author{
Leili Väisa, Jaan Ereline, Mati PäÄsuke, Tatjana Kums \\ Institute of Sport Sciences and Physiotherapy, University of Tartu, Tartu, Estonia
}

\begin{abstract}
The aim of the present study was to establish the changes that occur in dancers' static body balance indicators during rest, in case of interfering factors and in stress condition. The sample consisted of 14 advanced female folk dancers at the age of 16-20 years. The participants' static body balance was measured at the beginning (in the autumn) and at the end (in the spring) of the eight-month dancing period. Static body balance indicators were registered on a dynamographic platform within 30 seconds, standing on bipedal on stable and unstable support surface in eyes-open (EO) and eyes-closed (EC) conditions. The Flamingo test balance control, the balance control after spinning around and jumping tests were conducted only in EO condition. The following parameters were registered: the movements of the centre of pressure $(\mathrm{CoP})$ in the anterior-posterior (AP) and medio-lateral (ML) dimensions; the length, speed and area of the trajectory. According to the study, folk dancers' CoP movements in the AP and ML dimensions, measured in different conditions (EO, EC), on stable and unstable support surface, did not change significantly after the eight-month dancing practice. The young folk dancers' static body balance, assessed by CoP movement trajectory, speed and area, improved considerably over the eight-month training period. Flamingo test results indicate that practising folk dance develops the young female folk dancers' right and left side static stability equally. In the context of Estonian folk dance practice, including preparation for performing at dance festival, the young female folk dancers' balance performance improved both in vestibular instability (spins, standing on unstable support surface and in EO condition) and fatigue (jumping test) conditions.
\end{abstract}

Keywords: Estonian folk dance practice, balance performance, centre of pressure 


\section{INTRODUCTION}

Balance or postural stability is the ability to control the centre of pressure $(\mathrm{CoP})$ in relationship to the base of support. Maintaining postural stability is a complex process and requires postural control that is based on the interaction of musculoskeletal and neural systems. Postural control involves controlling the body's position in space and maintaining its vertical orientation. Vertical orientation is established with the help of multiple sensory references, including gravity (the vestibular system), the support surface (somatosensory system), proprioception, and the relationship of the body to objects in the environment (visual system) [13].

Standing balance is the ability to stand with as little sway as possible. Balance can be assessed in a quiescent state, bipedal- or unipedal standing on a stable surface with eyes open, closed, or standing on an unstable surface, or following a specific perturbation, e.g. jump, sudden stop, spinning around [4].

Balance ability is dependent on several factors: first, body alignment can minimize the effect of gravitational forces; second, muscle tone keeps the body from collapsing in response to the pull of gravity. With an upright stance increases the activity of postural muscles to counteract the force of gravity, this is referred to as postural tone. Inputs from the visual and vestibular systems also influence postural tone. Research suggests that postural control involves sensory processing, with constant mapping of perception to action, so that the postural system can calculate where the body is located in space and can predict where it is going and which actions are necessary for controlling this movement [13].

Dance integrates movement, postural balance and the multiple aspects involved with postural control [2]. The balance ability was examined in a group of 18 contemporary dancers and 30 non-dancers in different visual conditions. The task involved maintaining balance for 30 s on a stability platform with open and closed eyes. The results showed that dancers exhibited greater balance ability than non-dancers only in the eyes-open task. The greater postural control exhibited by dancers depends on the availability of visual information [12]. Other researchers have also yielded results confirming that visual information is important in dancers' postural control process, proven by increased dislocations of the $\mathrm{CoP}$ without visual feedback [10]. Kiefer et al. [7] investigated the multi-segmental postural coordination in professional ballet dancers. The results indicated that increased coordination, stability, potentially achieved through enhanced neuromuscular control and perceptual sensitivity enable dancers to perform complex balance tasks. 
Dancers exhibited less variable ankle-hip coordination and less deterministic ankle-hip coupling, compared to controls [7].

More investigations have been conducted on the effects of folklore dance on postural control ability. Dewhurst. et.al. [3] examined the effect of Scottish country dance on postural stability. Dancers were compared with physically active controls for static postural sway measured on a force platform. The dancers' group had smaller sway velocity for all tests, except for Tandem with eyes closed [3]. Krityakiarana and Jongkamonwiwat [8] compared Thai classical dancers and non-dancers with balance abilities tests in different balance conditions, whereas Thai classical dancers demonstrated better ability to maintain postural stability during different challenging postural tests [8]. Balance and muscle strength in elderly women who practice Samba dance were investigated by Serra et al. [14]. Samba dancers had better postural balance outcomes with eyes closed in comparison with nondancers, but no differences emerged between dancers and non-dancers in muscle strength [14].

Different dances and their training systems have versatile movement patterns and choreography, but similarly to classical ballet dancers, practising folklore dance may change and improve performance in balance tests of participants, compared to non-dancers. It has also been stated that traditional dance is an effective means of physical activity for improving static and dynamic balance control and also lifespan in the elderly [15].

In the present study we investigated the effect of Estonian folk dance training on static balance performance in young females. To our knowledge, the training of Estonian folk dancers has not been examined in its scientific aspects before.

\section{METHODS}

\section{Subjects}

14 advanced young female Estonian folk dancers of Antsla dance club "Pärliine" and Tartu dance club "Just" participated in this study. The mean $( \pm \mathrm{SD})$ age, body height, body mass and body mass index of the subjects were $17.81 \pm 1.35$ years; $165.86 \pm 4.28 \mathrm{~cm} ; 56.5 \pm 4.4 \mathrm{~kg} ; 20.57 \pm 1.65 \mathrm{~kg} / \mathrm{m}^{2}$, respectively. The subjects had regularly trained dancing since $7.29 \pm 2.66$ years, they had 3-4 training days per week and training duration was 1.5-2 hours per day. Both dance groups participated in the Estonian Youth Dance Festival "Maa ja ilm" in 2011. The participants' written informed consent was obtained. The study was carried out in the Laboratory of Kinesiology and Biomechanics of the University of Tartu in 2011-2012. 


\section{Experimental protocol}

The participants' static body balance was measured at the beginning (in the autumn) and at the end (in the spring) of the eight-month dancing period. The purpose of the study and procedures were explained to the subjects and all questions were answered. After a light warm-up the subjects' body height and weight were measured. The static balance testing was performed on the dynamographic force platform Kistler 9286A (Switzerland) during 30- second bipedal standing on stable and unstable "foam" (Alcan Airex AG, Switzerland, 50x41 cm) support surface with eyes open (EO) and eyes closed (EC) (Figure 1, A). Next were performed the Flamingo test (Figure 1, B), jumping test (induction of fatigue) consisting of 16 repetitive Sauté jumps (Figure 1, C) and 10-time spinning around test (vestibular stimulation) in the sitting position (Figure 1, D).
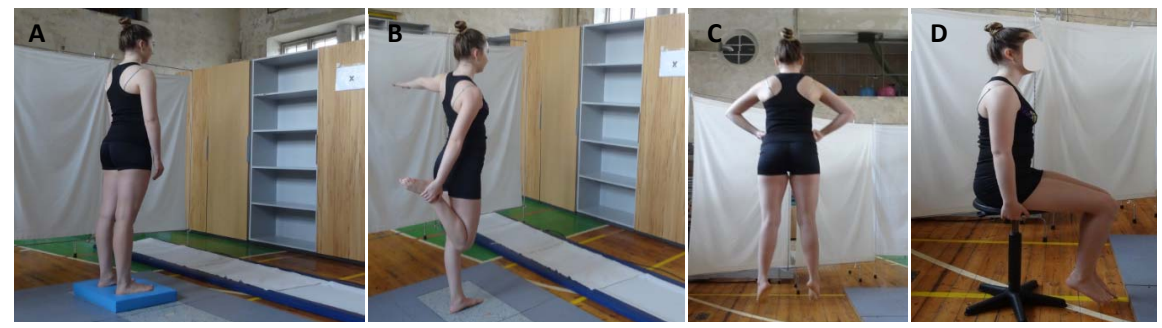

Figure 1. The standing on "foam" (A); Flamingo test standing on right and left legs (B); Jumping test performance (C); Spinning around test performance (D).

The following body sway characteristics were recorded by movement analysis system Elite Clinic and SWAY software (BTS S.p.A): (1) CoP sways displacement in the anterior-posterior (AP) ( $\mathrm{mm}$ ) and mediolateral (ML) (mm) direction; (2) CoP trajectory length ( $\mathrm{mm}$ ); (3) CoP displacement speed $(\mathrm{mm} / \mathrm{s})$; (4) CoP movement equivalent area $\left(\mathrm{mm}^{2}\right)$. The subjects were familiarized with the positions before testing.

\section{Statistical analysis}

Statistical analysis was performed using the STATISTICA (version 13-3) software. Results are expressed as mean values (mean) and standard deviations $( \pm \mathrm{SD})$. The changes in static body balance, measured in the autumn and during the follow-up study after 8 months were assessed by one-way (ANOVA) Tukey post hoc tests. To measure the inner group differences paired t-test was used. Statistical significance was accepted at $\mathrm{p}<0.05$. 


\section{RESULTS}

\section{Anthropometric characteristics}

No significant differences were found in physical characteristics of the subjects, measured in the autumn, before dance training period and during follow-up study after 8-month dance training in the spring (Table 1).

Table 1. The physical characteristics of the subjects (mean \pm SD).

\begin{tabular}{lccc}
\hline Variables & Autumn $(\mathrm{n}=14)$ & Spring $(\mathrm{n}=14)$ & $\mathrm{p}$-value \\
\hline Age (years) & $17.00 \pm 1.52$ & $17.64 \pm 1.50$ & 0.270 \\
\hline Height $(\mathrm{cm})$ & $165.79 \pm 4.32$ & $166.43 \pm 3.94$ & 0.684 \\
\hline Body mass $(\mathrm{kg})$ & $56.57 \pm 4.29$ & $56.64 \pm 4.47$ & 0.966 \\
\hline BMI $\left(\mathrm{kg} / \mathrm{m}^{2}\right)$ & $20.57 \pm 1.65$ & $20.60 \pm 1.68$ & 0.962 \\
\hline
\end{tabular}

$\mathrm{BMl}$ - body mass index.

\section{CoP sways displacement in AP and ML direction}

In balance tests of the folk dancers group no significant differences were found in CoP displacement in AP and ML direction while standing on a stable and unstable surface EO and EC (Table 2), and in jumping and spinning around tests performed after the eight-month training period (Table 3).

Table 2. CoP displacement in AP and ML direction in standing on stable and "foam" surface EO and EC (mean \pm SD).

\begin{tabular}{lcccccc}
\hline \multirow{2}{*}{$\begin{array}{l}\text { CoP } \\
\text { sway }\end{array}$} & \multicolumn{7}{c}{ Standing on stable surface } \\
\cline { 2 - 7 } & $\begin{array}{c}\text { Autumn } \\
(\mathrm{n}=14)\end{array}$ & $\begin{array}{c}\text { Spring } \\
(\mathrm{n}=14)\end{array}$ & & $\begin{array}{c}\text { Autumn } \\
(\mathrm{n}=14)\end{array}$ & $\begin{array}{c}\text { Spring } \\
(\mathrm{n}=14)\end{array}$ & -value \\
\hline AP $(\mathrm{mm})$ & $19.73 \pm 7.48$ & $20.54 \pm 7.39$ & 0.776 & $20.18 \pm 5.24$ & $22.03 \pm 7.23$ & 0.445 \\
\hline $\mathrm{ML}(\mathrm{mm})$ & $14.33 \pm 11.39$ & $13.87 \pm 6.51$ & 0.897 & $13.40 \pm 5.29$ & $15.54 \pm 6.76$ & 0.360 \\
\hline \multicolumn{7}{c}{ Standing on unstable surface "foam" } \\
\hline $\mathrm{AP}(\mathrm{mm})$ & $30.05 \pm 4.27$ & $29.77 \pm 8.77$ & 0.915 & $55.70 \pm 9.23$ & $56.77 \pm 16.97$ & 0.857 \\
\hline $\mathrm{ML}(\mathrm{mm})$ & $22.15 \pm 4.90$ & $22.00 \pm 6.22$ & 0.944 & $39.48 \pm 7.27$ & $39.48 \pm 8.06$ & 1.000 \\
\hline
\end{tabular}

CoP - movement of the centre of pressure, AP - anterior-posterior, ML - media-lateral, EO - eyes-open, EC - eyes closed[Insert Table 2 about here]. 
Table 3. CoP displacement in AP and ML direction after jumping and spinning around tests performance (mean \pm SD).

\begin{tabular}{|c|c|c|c|}
\hline \multirow[t]{2}{*}{$\begin{array}{l}\text { CoP sway } \\
\text { direction }\end{array}$} & \multicolumn{2}{|c|}{ Body CoP displacement after jumping test performance } & \multirow[t]{2}{*}{ p-value } \\
\hline & Autumn $(n=14)$ & Spring $(n=14)$ & \\
\hline $\mathrm{AP}(\mathrm{mm})$ & $24.59 \pm 8.23$ & $22.16 \pm 8.98$ & 0.462 \\
\hline $\mathrm{ML}(\mathrm{mm})$ & $16.07 \pm 4.68$ & $16.44 \pm 4.74$ & 0.837 \\
\hline \multicolumn{4}{|c|}{ Body CoP displacement after spinning around test } \\
\hline $\mathrm{AP}(\mathrm{mm})$ & $26.81 \pm 10.28$ & $23.84 \pm 13.72$ & 0.523 \\
\hline $\mathrm{ML}(\mathrm{mm})$ & $23.50 \pm 7.77$ & $18.94 \pm 12.73$ & 0.263 \\
\hline
\end{tabular}

$\mathrm{CoP}$ - movement of the centre of pressure, AP - anterior-posterior, ML - media-lateral

No significant differences in these parameters were found in the Flamingo test either, performed in the standing position on the left and right leg (Table 4).

Table 4. CoP displacement in $\mathrm{AP}$ and $\mathrm{ML}$ direction in Flamingo test performance (mean \pm SD).

\begin{tabular}{lcccccc}
\hline $\begin{array}{l}\text { CoP } \\
\text { sway }\end{array}$ & \multicolumn{2}{c}{$\begin{array}{c}\text { Flamingo test on } \\
\text { left leg EO }\end{array}$} & p-value & \multicolumn{2}{c}{$\begin{array}{c}\text { Flamingo test } \\
\text { on right leg EC }\end{array}$} & p-value \\
\hline & $\begin{array}{c}\text { Autumn } \\
(\mathrm{n}=14)\end{array}$ & $\begin{array}{c}\text { Spring } \\
(\mathrm{n}=14)\end{array}$ & & $\begin{array}{c}\text { Autumn } \\
(\mathrm{n}=14)\end{array}$ & $\begin{array}{c}\text { Spring } \\
(\mathrm{n}=14)\end{array}$ & \\
\hline $\mathrm{AP}(\mathrm{mm})$ & $39.66 \pm 5.84$ & $43.87 \pm 16.90$ & 0.390 & $39.49 \pm 8.80$ & $40.40 \pm 14.28$ & 0.841 \\
\hline $\mathrm{ML}(\mathrm{mm})$ & $28.11 \pm 3.19$ & $30.52 \pm 9.26$ & 0.366 & $26.71 \pm 4.05$ & $26.80 \pm 4.74$ & 0.957 \\
\hline
\end{tabular}

$\mathrm{AP}$ - anterior-posterior, ML- media-lateral, E - eyes open, EC - eyes closed.

\section{Speed of CoP sway, trace length and equivalent area}

Significant differences were found in the speed of CoP sway $(\mathrm{p}<0.0001)$ in bipedal standing on stable and unstable surface $\mathrm{EO}$ and $\mathrm{EC}$, in the Flamingo test, spinning around and jumping tests performance (Figure 2, A). 


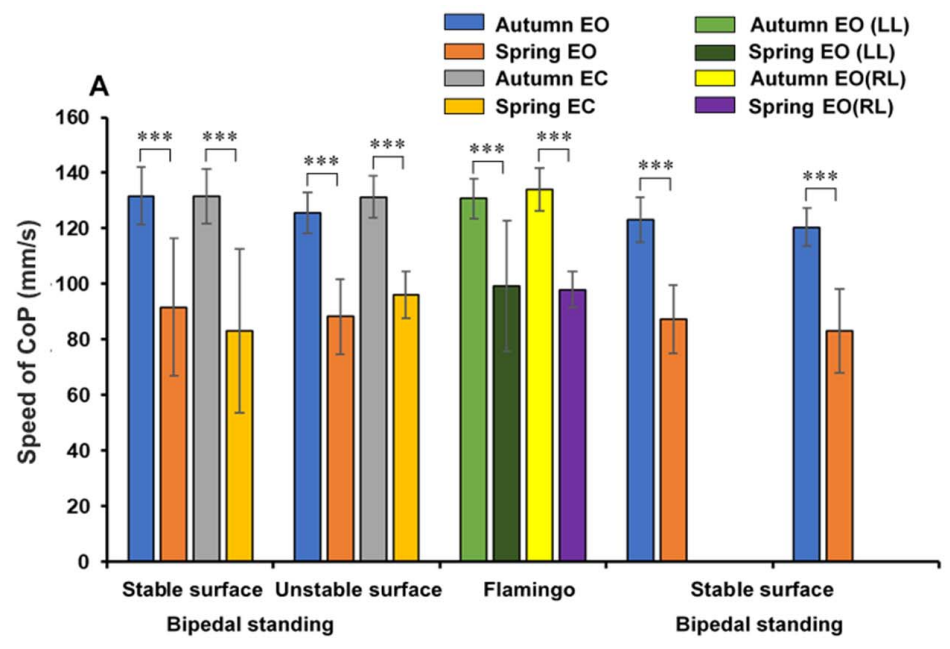

After jumping and spinning

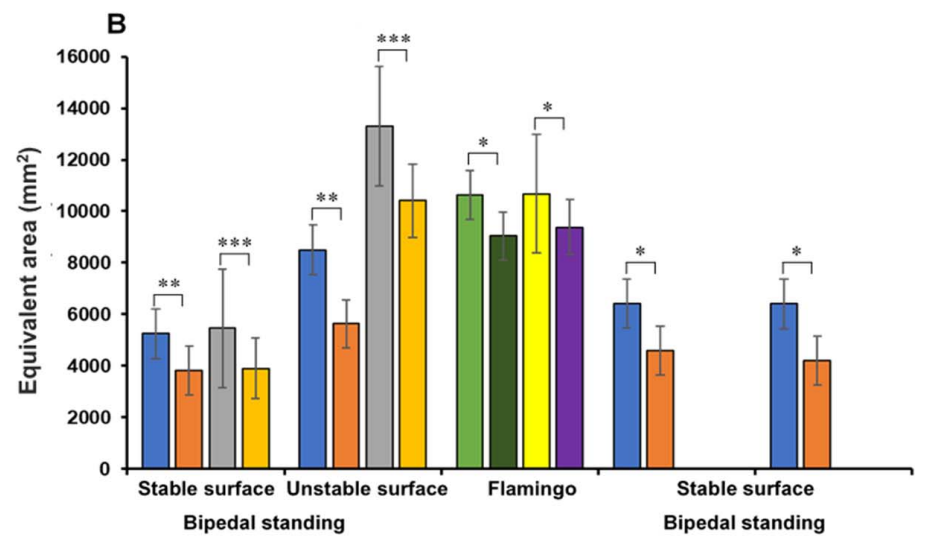

C

After jumping and spinning

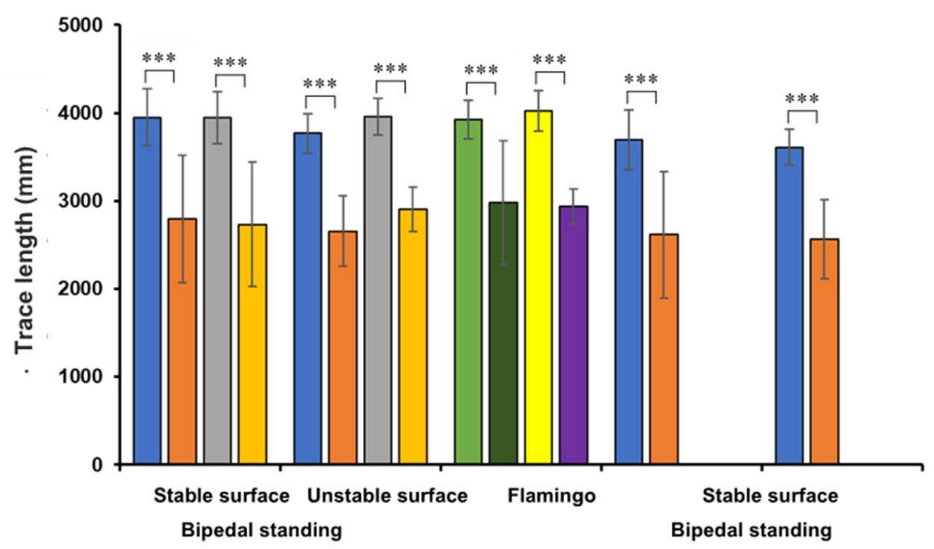

Figure 2. Speed of CoP sway (A); Equivivalent area of CoP sway (B); Trajectory length of CoP sway (C). 
Significant differences $(\mathrm{p}<0.0001)$ were found also in the trajectory length of CoP sway (Figure 2, C), and in equivalent area of CoP sway $(\mathrm{p}<0.05)$ for all above conditions (Figure 2, B).

\section{DISCUSSION}

We investigated the influence of 8-month folk dance training on static balance performance in young females in the follow-up study.

The young female folk dancers' CoP displacement in the AP and ML direction measured in bipedal standing on stable and unstable surface in EO and EC condition, in the Flamingo test, spinning around and jumping tests performance did not change significantly during the eight-month training period. In the spring above mentioned parameters improve only by $1.1 \%$.

Previous studies $[13,16]$ indicated that CoP displacements in AP and ML direction characterize postural behaviour, being spontaneous attempts at attaining relative stability of the body's segmented structure and is related to support surface stability and its size [13]. If surface conditions during the test period are steady, the postural control of CoP displacement in AP and ML directions remains unchanged in healthy adults without neuromuscular disorders [9]. It was also seen in this study that during 8-month folk dance training CoP displacement in AP and ML direction in standing on stable surface did not change.

Brumagne et al. [1] demonstrated that during standing on unstable surface "foam" the CNS of healthy persons significantly up-weighted the proprioceptive signals from the paraspinal muscles and down-weighted those from the ankle muscles to control postural balance. Ivanenko et al. [6] showed that when standing on "foam" there is inherently less reliable proprioceptive input from the ankle joints. Patel et al. [11] stated that in standing on "foam" can cause mechanical perturbation as compression of the compliant visco-elastic surface reduces the effectiveness of ankle torque required for postural stabilisation and mechanoreceptive information is affected by compliant surfaces. The input to the mechanoreceptors on the soles of the feet is affected and balance deficit emerges [11]. The outcomes of the present study indicated that in Estonian folk dancers postural deficit did not emerge during standing on unstable surface "foam".

Standing on a narrow-based surface invokes a change in balance strategy from ankle to hip to the trunk, and in the degree of control of stiffness and this evokes increasing of the CoP displacement in AP and ML directions [16, 17]. It is noteworthy that in the present study, performance CoP displacement in AP and ML directions in standing on the right and left leg during 
the Flamingo tests was similar, and significant differences were not found in the follow-up study after 8-month folk dance training. Proceeding from the results of the Flamingo tests, we may conclude that folk dance training in young females developed the body postural stability on the left and right side equally. The greater stability on the one leg standing in EO condition has also been demonstrated in ballet dancers compared with non-dancers [7].

Kiefer et al. [7] suggest that ballet dancers have increased coordination, stability, potentially achieved through enhanced neuromuscular control and perceptual sensitivity.

The visual inputs have an important influence on postural control [4, 11, 13]. The results of Michalska et al. [10] studies showed that the postural control of the dancers is strongly dependent on the availability of visual information. These results are explained by the fact that the dance training requires constant visual control, which is ensured during practice by mirror and very frequent pirouettes routines require proper eyesight fixation [10].

Folklore dancers, however, demonstrate high postural control ability in the EO and EC condition [14]. Muelas Pérez et al. [12] stated that folk dancers exhibited greater balance ability only in EO task compared to nondancers, but only dancers reduced their complexity in EC task [12]. Samba dancers were investigated by Serra et al. [14]. In comparison with the nondancers, Samba group participants were better in postural balance outcomes with EC, but there were no differences between dancers and non-dancers in muscle strength [14].

Estonian folk dancers in our study demonstrated high balance ability with EC in standing on stable and unstable "foam" surface and EO on a narrow-based surface (Flamingo test). Our results showed that the good balance ability did not change during 8-month folk dance training.

Hopper et al. [5] investigated the effects of vestibular stimulation (pirouettes) and fatigue (repetitive jumps) on postural control in classical ballet dancers, the purpose of that study was the same than in our study. Hopper et al. [5] stated that the professional dancer's balance was unaffected by both the vestibular stimulation and the fatigue task. The pre-professional and recreational dancers' static sway increased following both perturbations. It is concluded that professional dancers are able to compensate for vestibular and fatiguing perturbations due to a higher level of skill-specific motor training [5]. This result is accordance with our outcome that the in Estonian folk dancers static sway significantly decreased following specific perturbations - spinning around and jumping tests performance, after about 8 -month folk dance training. We may also conclude that this occurred due to a high level of skill-specific motor training. 
In the present study $\mathrm{CoP}$ sway trajectory length, speed and equivalent area in young folk dancers after 8-month dance training significantly decreased in all exercises (tasks).

Marked improvement of the body stability took place in standing on a stable surface with EC, while CoP sway trajectory length decreased by $31 \%$, speed $37 \%$ and area $29 \%$ and in EO condition improvements were 29\%, 30\% and $27 \%$, respectively. In standing on "foam" with EO, CoP sway trajectory length and speed decreased by $30 \%$ and area $34 \%$, and in the EC condition by $27 \%$ and $22 \%$, respectively.

With the spinning around test we investigated the effects of vestibular stimulation on postural stability in folk dancers. After vestibular stimulation CoP sway trajectory length, speed and area decreased by $29 \%$. The results of jumping test performance showed that CoP sway trajectory length decreased by $29 \%$, speed $31 \%$ and area by $34 \%$, respectively. Thereby, the results of this study indicate that the vestibular and proprioceptive sensitivity in folk dancers significantly improved due to specific folk dance training.

In conclusion, this study demonstrated that 8-month training significantly improved postural balance ability in young Estonian folk dancers in the context of the dance festival preparations.

\section{REFERENCES}

1. Brumagne S, Janssens L, Knapen S, Claeys K, Suuden-Johanson E.(2008) Persons with recurrent low back pain exhibit a rigid postural control strategy. Eur Spine J, 17: 1177-1184. https://doi.org/10.1007/s00586-008-0709-7

2. Costa MS, Ferreira AS, Felicio LR. (2013) Static and dynamic balance in ballet dancers: a literature review. Fisioterapia e Pesquisa, 20(3): 299-305. https://doi.org/10.1590/S1809-29502013000300016

3. Dewhurst S, Peacock L, Bampouras TM. (2015) Postural stability of older female Scottish country dancers in comparison with physical active controls. J Aging Phys Act, 23(1): 128-132. https://doi.org/10.1123/JAPA.2013-0050

4. Gerbino PG, Griffin ED, Zurakowski D. (2006) Comparison of standing balance between female collegiate dancers and soccer players. Gait \& Posture, 26: 501-507. https://doi.org/10.1016/j.gaitpost.2006.11.205

5. Hopper D, Grisbrook T, Newnham P, Edwards D. (2014) The effects of vestibular stimulation and fatigue on postural control in classical ballet dancers. J Dance Med Science, 18(2): 67-73. https://doi.org/10.12678/1089-313X.18.2.67

6. Ivanenko YP, Solopova IA, Levik YS. (2000) The direction of postural instability affects postural reactions to ankle muscle vibration in humans. Neurosci Lett, 292: 103-106. https://doi.org/10.1016/S0304-3940(00)01438-5 
7. Kiefer AW, Riley MA, Shockley K, Sitton CA, Hewett TE, Cummins-Sebree S, Haas JG. (2011) Multi-segmental postural coordination in professional ballet dancers. Gait \& Posture, 34(1): 76-80.

https://doi.org/10.1016/j.gaitpost.2011.03.016

8. Krityakiarana W, Jongkamonwiwat N. (2016) Comparison of balance performance between Thai classical dancers and non-dancers. J Dance Med Sci, 20(2): 72-78. https://doi.org/10.12678/1089-313X.20.2.72

9. McClenaghan BA, Williams H, Dickerson J, Thombs L.(1994) Spectral signature of forces to discriminate perturbations in standing posture. Clin Biomech, 9: 21-27. https://doi.org/10.1016/0268-0033(94)90054-X

10. Michalska J, Kamieniarz A, Fredyk A, Bacik B, Juras G, Słomka KJ. (2018) Effect of expertise in ballet dance on static and functional balance. Gait \& Posture, 64: 68-74. https://doi.org/10.1016/j.gaitpost.2018.05.034

11. Patel M, Fransson PA, Lush D, Gomez S. (2007) The effect of foam surface properties on postural stability assessment while standing. Gait \& Posture, 28: 649-656. https://doi.org/10.1016/j.gaitpost.2008.04.018

12. Muelas Pérez R, Solana RS, Murillo DB, Hernández FJM. (2014) Visual availability, balance performance and movement complexity in dancers. Gait \& Posture, 40: 556-560. https://doi.org/10.1016/j.gaitpost.2014.06.021

13. Shumway-Cook A, Woollacott M. (2007) Normal Postural Control in "Motor Control: Translating Research into Clinical Practice”. Philadelphia. Lippincott Williams \& Wilkins.

14. Serra MM, Alonso AC, Peterson M, Mochizuki L, Greve JMD, Garcez-Leme LE. (2016) Balance and muscle strength in elderly women who dance Samba. PloS One, 11: e0166105. https://doi.org/10.1371/journal.pone.0166105

15. Sofianidis G, Hatzitaki V, Douka S, Grouios G. (2009) Effect of a 10-week traditional dance program on static and dynamic balance control in elderly adults. J Aging Phys Act, 17(2): 167-180. https://doi.org/10.1123/japa.17.2.167

16. Sullivan EV, Rose J, Rolfing T, Pfefferbaum A. (2009) Postural sway reduction in aging men and women: relation to brain structure, cognitive status, and stabilizing factors. Neurobiol Aging, 30: 793-807. https://doi.org/10.1016/j.neurobiolaging.2007.08.021

17. Winter DA, Patla AE, Prince F, Ishac M, Gielo-Perczak K. (1998) Stiffness control of balance in quiet standing. J Neurophysiol, 80(3): 1211-1221. https://doi.org/10.1152/jn.1998.80.3.1211

\section{Correspondence to:}

\section{Tatjana Kums}

Institute of Sport Sciences and Physiotherapy

University of Tartu

Ujula 4, 51008 Tartu, Estonia

E-mail: tatjana.kums@ut.ee 